\title{
Acute Monoblastic and Monocytic Leukemia in Remission
}

National Cancer Institute

\section{Source}

National Cancer Institute. Acute Monoblastic and Monocytic Leukemia in Remission. NCl

Thesaurus. Code C156725.

Acute monoblastic and monocytic leukemia which is not growing and responds to treatment. 